\title{
COMPARISON BETWEEN ANTIOXIDANT EFFECT OF VITAMIN-C ALONE AND ITS COMBINATION TO VITAMIN-E IN LONG EVANS NORWEGIAN RAT
}

\author{
MOHAMMED IKRAM ULLAH KHAN ${ }^{1}$, SELIM MOHAMMED JAHANGIR ${ }^{2}$, SYEDA RAZIA KARIM ${ }^{3}$, A.K.M. NURUL ANWAR 4 . \\ ${ }^{1}$ Professor (CC), Department of Pharmacology, BGC Trust Medical College, Chittagong, ${ }^{2}$ Associate Professor, \\ Department of Pharmacology, Chittagong Medical College, Chittagong, ${ }^{3}$ Department of Gynae \& Obs., Chittagong \\ Medical College Hospital, ${ }^{4}$ Professor of Pharmacology and Principal, Ibrahim Medical College, Dhaka
}

\begin{abstract}
In rat myocardial damage was produced the administration of adrenaline in a dose of $2 \mathrm{mg} / \mathrm{kg}$ body weight (b.w.) subcutaneously for 2 consecutive mornings. This damage was assessed indirectly by significant increase in serum aspertate transminase (AST) and directly by microscopic changes in the myocardium.

Pretreatment with the vitamin-C in a dose $10 \mathrm{mg} / \mathrm{kg}$ body weight subcutaneously and preteatment with the combination of vitamin-C in a dose of $10 \mathrm{mg} / \mathrm{kg}$ b.w. subcutaneously and vitamin-E in a dose of $50 \mathrm{mg} / \mathrm{kg}$ b.w. orally for 10 days prevented the adrenaline induced myocadial damage equally which was evidenced by the equal prevention in the rise of serum AST \& LDH levels as well as equal prevention of microscopic changes of the myocardium by the adrenaline.
\end{abstract}

(Bangladesh J Physiol Pharmacol 2007; 25(1\&2) : 16-19)

\section{INTRODUCTION}

Heart disease is one of the major health problems throughout the world. Among the heart diseases, the ischemic heart disease (IHD) is the most important cause (about 80\%) of cardiac death. Ischemia occurs as a result of critical imbalance between coronary blood flow and myocardial demand ${ }^{1}$. The myocardial damage produced by adrenaline is identical to that of human myocardial infarction $^{2,3}$.

In producing myocardial damage during ischemia, generation of oxygen derived free radicals are also involved besides other mechanisms. Free radicals are the chemical species that possess unpaired electron. During ischemia ATP level is depleted. It causes uncoupled mitochondrial respiratory burst chain which is responsible for the generation of oxygen-derived free radicals ${ }^{4}$. These free radicals then interact with the membrane phospholipid and causes peroxidation of polyunsaturated lipids in the membrane. Antioxidants can trap these free radicals. Vitamin- $C$ also acts as an antioxidant by reacting directly with the aqueous free radicals. Vitamin-E is also a lipophilic radical scavenging antioxidant ${ }^{5}$.

Correspondence : Dr. Mohammed Ikram Ullah Khan, Professor (CC), Department of Pharmacology, BGC Trust Medical College, Chittagong.

\section{MATERIALS AND METHODS}

The experiment was carried out on a total number of 60 Long Evans Norwegian rats of both sexes. They were 3-5 months old, weighing between 150-250 gm. They fed on standard laboratory diet and were allowed to drink water ad.libitum. The rats were divided into 6 groups. Total duration of experiment was 10 days. First two groups received distilled water (vehicle) and adrenaline (2mg/ $\mathrm{kg}$ b.w. subcutaneously) for 2 consecutive days i.e. - on the $9^{\text {th }}$ and $10^{\text {th }}$ day of the experiment respectively. Third group received vitamin-C (10mg/kg b.w. s/c) for 10 days and adrenaline (2mg/kg b.w. subcutaneously) for 2 days i.e. - on the 9th and 10th day. Fourth group received vitamin-C (10gm/kg b.w. s/c) for 10 days and adrenaline ( $2 \mathrm{mg} / \mathrm{kg}$ b.w. subcutaneously) for 2 consecutive days i.e. - on the $9^{\text {th }}$ and $10^{\text {th }}$ day. Fifth group received combination of vitamin-C (10mg/kg b.w. subcutaneously) and vitaminE (50gm/kg b.w. orally) for 10 days. Sixth group received combination of vitamin-C (10mg/kg b.w. s/c) and vitamin$E$ (50mg/kg b.w. orally) for 10 days and adrenaline (2mg/ $\mathrm{kg}$ b.w. s/c) for 2 days i.e. - on the $9^{\text {th }}$ of 10 day.

All the rats were sacrificed on the $11^{\text {th }}$ day i.e. -48 hours after $1^{\text {st }}$ adrenaline injection under light anesthesia with chloroform. By cutting neck blood was collected and the serum was separated for estimation of aspertate transminase (AST) and lactate dehydrogenase (LDH) by standard kits supplied by Boehringer, Germany. The hearts were preserved in formalin for histopathological 
examination. Haematoxylin and eosin stain was done for Mythological study of the myocardium. Statistical analysis of result was done by unpaired student's "T" test.

\section{RESULT}

There were highly significant $(p<0.001)$ rise in serum AST and significant $(p<0.01)$ rise in serum LDH levels following adrenaline injection as compared to those of control group (Table -I).

In the histological study of the myocardial tissue $60 \%$ of the animals showed severe degree of myocardial damage as evidence by the mononuclear cellular infiltration, interstitial oedema formation, fragmentation of muscle fibres and vacuolar degeneration as compared to those of control group where normal architecture of the myocardiam was maintained (Table - II).

The group which received vitamin-C (Group III) there were no rises in serum AST and LDH levels like adrenaline-only treated group. So the results were highly significant $(p<0.001)$ in serum AST and LDH levels as compared to those of adrenaline treated group (Table1). Normal architecture of the myocardium was also maintained (Table-II).
In the group pretreated with vitamin -C followed by adrenaline (Group-IV) there were also no rise in serum AST and LDH levels like adrenaline treated group. So the results were significant in serum AST $(p<0.05)$ and $\mathrm{LDH}(\mathrm{p}<0.01)$ levels as compared to those of adrenaline treated group (Table-I). Normal architecture of the myocardium was also maintained (Table-II)

The group which received vitamin $-C$ and $-E$ combination there were no rise in serum AST and LDH levels like adrenaline only treated group. So the result were significant $(p<0.01)$ in serum AST and highly significant $(p<0.001)$ in serum LDH levels as compared to those of adrenaline treated group (Table-I). Normal architecture of the myocardium was also maintained (Table - II).

In the group pretreated with vitamin-C and $-E$ combination followed by adrenaline there were also no rise in the serum AST and LDH levels like adrenaline treated group. So the result were significant $(p<0.01)$ in serum AST and highly significant $(p<0.001)$ in serum $\mathrm{LDH}$ levels as compared to those of adrenaline treated group (Table-I). Myocardial histology showed no microscopic changes (Table-II).

Table - I

Comparison of the effects of vitamin-C alone and vitamin-C and $-E$ combination in serum AST and LDH levels in adrenaline treated rats

\begin{tabular}{|c|c|c|c|c|}
\hline \multicolumn{2}{|c|}{ Groups } & \multirow{2}{*}{$\frac{\text { Enzyme }}{\text { AST }}$} & \multirow{2}{*}{$\frac{\text { Mean } \pm \text { SE }(U / L)}{14.97 \pm 2.8}$} & \multirow{2}{*}{$\frac{95 \% \text { confidencelimit }}{(9.48-20.46)}$} \\
\hline I & & & & \\
\hline & (Control) & LDH & $60.92 \pm 12.97$ & $(35.5-86.34)$ \\
\hline \multirow[t]{2}{*}{ ॥ } & Adrenaline & AST & $44.07 \pm 3.98^{\star \star \star}$ & $(36.27-51.87)$ \\
\hline & (2 mg/kg b.w. orally) & $\mathrm{LDH}$ & $124.2 \pm 7.03^{\star \star}$ & $(110.42-137.98)$ \\
\hline \multirow[t]{2}{*}{ III } & Vitamin-C & AST & $16.88 \pm 4.16^{\star \star *}$ & (8.73-25.03) \\
\hline & (10 mg/kg. b.w. s/c) & $\mathrm{LDH}$ & $39.36 \pm 8.36^{\star \star \star}$ & $(22.97-55.75)$ \\
\hline \multirow[t]{2}{*}{ N } & Adrenaline (2 mg/kg b.w. s/c) & AST & $22.7 \pm 6.4^{*}$ & $(10.16-35.24)$ \\
\hline & + Vitamin-C (10 mg/kg b.w. s/c) & $\mathrm{LDH}$ & $85.3 \pm 6.14^{\star *}$ & $(73.27-97.33)$ \\
\hline \multirow[t]{2}{*}{ V } & Vitamin-C (10 mg/kg b.w. s/c)+ & AST & $22.7 \pm 3.24$ ** & $(16.35-29.05)$ \\
\hline & Vitamin-E (50 mg/kg b.w. orally) & $\mathrm{LDH}$ & $31.98 \pm 7.61^{\star \star *}$ & $(17.06-46.9)$ \\
\hline \multirow[t]{3}{*}{$\mathrm{V}$} & Adrenaline (2 mg/kg b.w. s/c) + & AST & $25.61 \pm 2.97^{\star \star}$ & $(22.64-31.43)$ \\
\hline & Vitamin-C (10mg/kg b.w. s/c)+ & $\mathrm{LDH}$ & 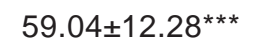 & $(34.47-83.11)$ \\
\hline & Vitamin-E (50mg/kg b.w. orally) & & & \\
\hline
\end{tabular}

Comparison made: I vs II, II vs III, II vs IV, II vs V, II vs VI, ${ }^{*}=p<0.05,{ }^{* *}=p<0.01,{ }^{* * *}=p<0.001$ 
Table II

Comparison of the effects of vitamin- $C$ alone and vitamin- $C \& E$ combination on myocardial histology in adrenaline treated rats.

\begin{tabular}{|c|c|c|c|c|c|c|}
\hline Lesions & Control & $\begin{array}{l}\text { Adrenaline } \\
(2 \mathrm{mg} / \mathrm{kg} \\
\text { b.ws/c) }\end{array}$ & $\begin{array}{l}\text { Vit-C (10mg/ } \\
\text { kg b.w s/c) }\end{array}$ & $\begin{array}{l}\text { Adrenaline } \\
(2 \mathrm{mg} / \mathrm{kgb} . \mathrm{w} \\
\text { s/c)+ Vit-C(10mg/ } \\
\text { kgb.w s/c) }\end{array}$ & $\begin{array}{l}\text { Vit-C(10mg } \\
\text { /kgb.w. s/c)+ } \\
\text { Vit-E(50mg/ } \\
\text { kgb.w orally) }\end{array}$ & $\begin{array}{l}\text { Adrenaline } \\
(2 \mathrm{mg} / \mathrm{kg} \mathrm{b} . \mathrm{ws} / \mathrm{c}+ \\
\text { Vit-C }(10 \mathrm{mg} / \\
\mathrm{kgb} . \mathrm{w} . \mathrm{s} / \mathrm{c}+\text { Vit- } \\
\mathrm{E}(50 \mathrm{mg} / \mathrm{kg} \\
\text { b.w orally) }\end{array}$ \\
\hline $\begin{array}{l}\text { Mononuclear } \\
\text { cellular } \\
\text { infiltration }\end{array}$ & - & $\begin{array}{l}+(1) \\
++(3) \\
+++(6)\end{array}$ & - & $\begin{array}{l}+(2) \\
++(1)\end{array}$ & - & $\begin{array}{l}+(2) \\
++(1)\end{array}$ \\
\hline $\begin{array}{l}\text { Interstitial } \\
\text { Oedema }\end{array}$ & - & $\begin{array}{l}++(3) \\
+++(5)\end{array}$ & - & $\begin{array}{l}+(2) \\
++(1)\end{array}$ & $+(2)$ & $\begin{array}{l}+(2 \\
++(1)\end{array}$ \\
\hline $\begin{array}{l}\text { Fragmentation } \\
\text { of muscle } \\
\text { fibers }\end{array}$ & - & $\begin{array}{l}+(1) \\
++(2) \\
+++(6)\end{array}$ & - & - & - & $\begin{array}{l}+(3) \\
++(1)\end{array}$ \\
\hline $\begin{array}{l}\text { Vacuolar } \\
\text { degeneration }\end{array}$ & - & $\begin{array}{l}++(4) \\
+++(3)\end{array}$ & - & $+(1)$ & - & $+(1)$ \\
\hline
\end{tabular}

$+=$ Mild degree of lesion

$++=$ Moderate degree of lesion

$+++=$ Severe degree of lesion

Figure in the Parentheses denote the numbers of heart examined.

\section{DISCUSSION}

In the present study, adrenaline was administered to produce myocardial lesion in experimental animals such as in rats. This was evidenced by the fact that serum AST and LDH levels were significantly elevated in adrenaline induced rats as compared to those of control group. The results are consistent with the finding of other investigators who conduct similar types of studies $4,6,7$. The increased enzyme levels were associated with severe degree of microscopical changes supporting myocardial damage. These are also in well agreement with others ${ }^{4,8-10}$. Vitamin-C has no significant effect on normal myocardium which was evidenced by the fact that there were no rise in serum AST and LDH levels like adrenaline alone treated group (Gr-II). Adrenaline induces histological changes were also not observed in the vitamin-C pretreated group (Table-II).

Vitamin-C and -E combination has no significant effect on normal myocardium which was evidenced by the facts that there were no rise in serum AST and LDH levels like adrenaline. Normal architecture of the myocardium was also maintained by vitamin- $C$ and $-E$ combination. But adrenaline induced myocardial damage was prevented by vitamin- $C$ and $-E$ combination. So, in the group pretreated with vitamin-C and $-E$ combination followed by adrenaline (group-VI) there were no rise in serum AST and LDH levels like adrenaline alone treated group. Adrenaline induced microscopical changes were also not observed in the vitamin- $C$ and $-E$ combination pretreated group (Table-II).

Ischemia is a condition in which blood flow is reduced to a level inadequate to meet the metabolic requirements of the tissue. During ischemia the condition may be suitable for the production of free radical entities. Oxygen-derived free radical may initiate or extend cellular injury during reperfusion of oxygen radicals suggested that once these compounds are produced they could readily interact with the membrane phospolipids. Myocardial membrane phospolipids contain substantial levels of unsaturated fatty acids. The diene bodies in these lipids represent reactive sites which could interact with oxygen radicals. Such radical lipid interactions would in turn cause structural rearrangement of unsaturated lipids and altered membrane integrity. The oxygen molecule is capable of producing reactions in the cell, forming highly reactive free radicals and inducing lipid peroxidation of membranes, altering their integrity and increasing their fluidity and permeability. The ischemic cardiac cell is the prime candidate for this reaction sequence and explain the molecular mechanism underlying the pathologic events related to membrane dysfunction ${ }^{11}$.

Vitamin-C can react directly with the aqueous free radicals and quench their reactivity. Since free radicals 
species have been associated with damaging effects to intracellular and extracellular structures, the antioxidant function of vitamin- $C$ is important in the protection of cellular functions ${ }^{12}$.

As cardioprotctive agent, the use of vitamin $-E$ is based on the assumption that vitamin-E acts primarily as a lipohilic radical scavenging antioxidant and suppresses the chain initiation and for chain propagation by donating its phenolic hydrogen to the oxygen radicals. It is generally accepted to be an antioxidant that inhibit membrane lipid peroxidantion and also an important structural component of biological membranes that stabilizes them. The tocopherol molecule consists of two functional domains, a hydrocarbon chain that is necessary for proper orientation of the molecule in the membranes and a chromanol nucleus that is responsible for its antioxidant properties. The ability of vitamin -E to attenuate myocardial injury result from the reduction of the accumulation of non-esterified fatty acids in the myocardium, preserve cardiac functional parameters and decrease tissue calcium and LDH release ${ }^{13}$.

Since vitamin-E can halt lipid peroxidantion by acting as a chain breaking antioxidant and is a prominent membrane constituent in cardiac muscle, the possibilities exists that vitamin-E could have both protective and therapeutic roles against cardiac ischemic reperfusion injury ${ }^{14}$.

There is synergism between vitamin-E and $-C$. This synergism may primarily due to facts that vitamin- $C$ probably has an exclusive function for the generation of vitamin-E at the interphase ${ }^{15}$. A low plasma level of lipid standardized vitamin- $\mathrm{E}$ and $-\mathrm{C}$ is a risk factor in early angina pectoris and arteriographically standardized IHD may be inversely related to plasma vitamin- $\mathrm{C}^{16}$.

The patients with IHD have increased plasma levels of thiobarbituric acid-reactive material i.e. an indicator of increased susceptibility of IDL towards lipid peroxidation, which can be decreased by vitamin-C and / or vitamin$\mathrm{E}^{17}$.

\section{REFERENCES}

1. Bono DP, Boon A. Diseases of the cardiovascular system. In: Edwards CRW bouchier IAD, editors. Davidson's principles and practice of medicine, $16^{\text {th }}$ ed. Edinburgh: ELBS with Churchill Livingstone, 1991:249-339

2. Rona G, Chappel $\mathrm{Cl}$, Balazs T, Gaudry B. An infact like myocardial leison and other toxic manifestation produced by isoproterenol in the rat. AMA Arch pathol 1959;67: 443455.
3. Hecht $\mathrm{HH}_{5}$ concepts of myocardial ischemia. Arch Intern Med 1948; 73:711-729.

4. Massey KD, Burton KP. Vitamin E and ischemia reperfusion injury in the heart. In: Mino M, Nakamura H, Diplock AT, Kayden $\mathrm{HJ}$, editors. Vitamin $\mathrm{E}$ - Its usefulness in health and in curing diseases, $1^{\text {st }}$ ed. Tokyo: Japan scientific society press and Basel: S, Karger, 1993:291-311.

5. Frei B, Stocker R, Ames AN. Antioxidant defense and lipid peroxidation in human blood plasma. Proc Natl Acad Sci USA 1988;85:9748-52.

6. Bhalla S, Barar ESK, Sharma ML. Isoprenaline induced myocardial damage and cardioprotective action of some beta-adrenoceptor blockers in albino rats. Indian J Med Res 1987; 85:77-84.

7. Khatun M. Cardioprotective effects of beta-blockers on qatecholamine induced myocardial damage in rats [thesis: M Phil., Pharmacology], Dhaka: University of Dhaka, 1994.

8. Raab W. The sympathogenic biochemical trigger mechanism of angina pectoris. Am J cardiol 1962; 37:576-590.

9. Khan DS, Rona G, Chappil CL. Isoproterenol induced cardiac necrosis. Annals New York Accad Scie 1966; 4:285-293.

10. Wroblewski F. Clinical significance of serum enzyme alterations associated with myocardial infarction. Am Heart J 1957,54:219-224.

11. Ferrari R, Ceconi C, Curello S, et. al., Oxygen free radicals and myocardial damage; protective role of thiol-containing agents. The Am J of Med 1991; 91 (suppl 3c):95S-110S.

12. Moser U, Bendich A, vitamin-C. In: Machlin LJ, editor. Handbook of vitamins, $2^{\text {nd }}$ ed. New York \& Basel: Marcel Dekker, Inc., 199I:pp. 195-232.

13. Massey KD, Burton KP, Free radical damage in neonatal rat cardiac myocyte cultures: Effects of alpha-tocopherol, trolox and phytol. Free radical biology and medicine 1990; 8:449-458.

14. Janero DR. Therapeutic potential of vitamin-E against myocardial ischemic-reperfusion injury. Free Rad Biol \& Med 1991; 10:315-324.

15. Gey KF, Pushka P, Jordan P, Moser UK. Inverse correlation between plasma vitamin-E and mortality from ischemic heart disease in cross-cultural epidemiology. Am J Clin Nutr 1991;53:32S-34S.

16. Riemersma RA, Wood DA, Macintyre CCA, Elton R, Gey $\mathrm{KF}$, Oliver MF. Low plasma vitamin-E and $\mathrm{C}$ increased the risk of angina in Scottish men. Ann NY Acad Sci 1989;570:291-5.

17. Stringer MD, Görög PG, Freemo A, Kakkar W. Lipid peroxides and atherosclerosis, Br Med J 1989;298:281284. 